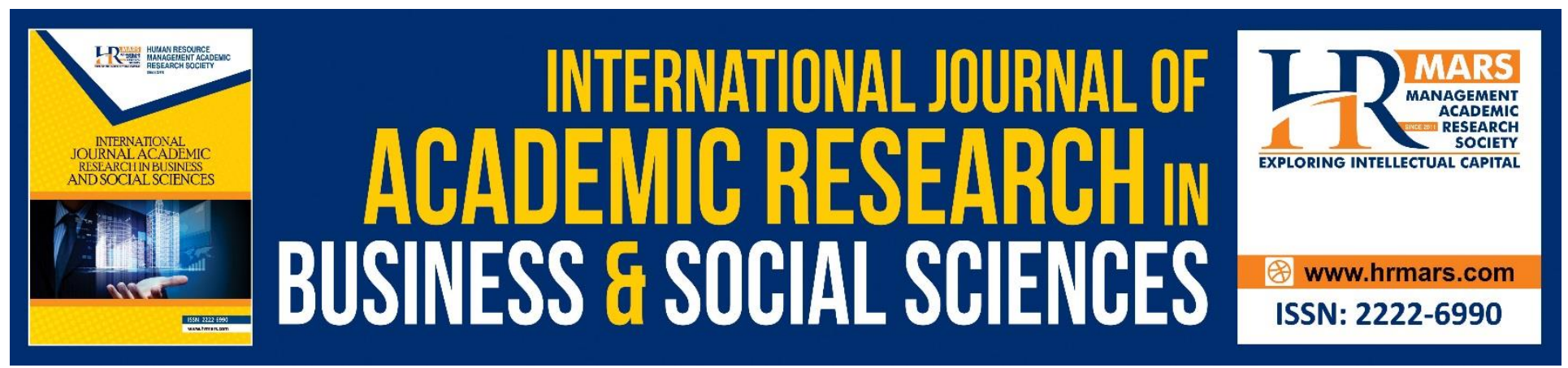

\title{
The Effects of Financing Sports Activities on International Sports Performance and on the Population's Health
}

\section{Razvan Dorel Pauna, Alexandra Pintea, Paul Sorin Lazar, Doru Maier}

To Link this Article: http://dx.doi.org/10.6007/IJARBSS/v10-i10/7910

DOI:10.6007/IJARBSS/v10-i10/7910

Received: 08 August 2020, Revised: 30 August 2020, Accepted: 19 September 2020

Published Online: 24 October 2020

In-Text Citation: (Pauna, Pintea, Lazar, \& Maier, 2020)

To Cite this Article: Pauna, R. D., Pintea, A., Lazar, P. S., \& Maier, D. (2020). The Effects of Financing Sports Activities on International Sports Performance and on the Population's Health. International Journal of Academic Research in Business and Social Sciences. 10(10), 950-965.

Copyright: (C) 2020 The Author(s)

Published by Human Resource Management Academic Research Society (www.hrmars.com)

This article is published under the Creative Commons Attribution (CC BY 4.0) license. Anyone may reproduce, distribute, translate and create derivative works of this article (for both commercial and non-commercial purposes), subject to full attribution to the original publication and authors. The full terms of this license may be seen at: http://creativecommons.org/licences/by/4.0/legalcode

Vol. 10, No. 10, 2020, Pg. 950 - 965

Full Terms \& Conditions of access and use can be found at http://hrmars.com/index.php/pages/detail/publication-ethics 


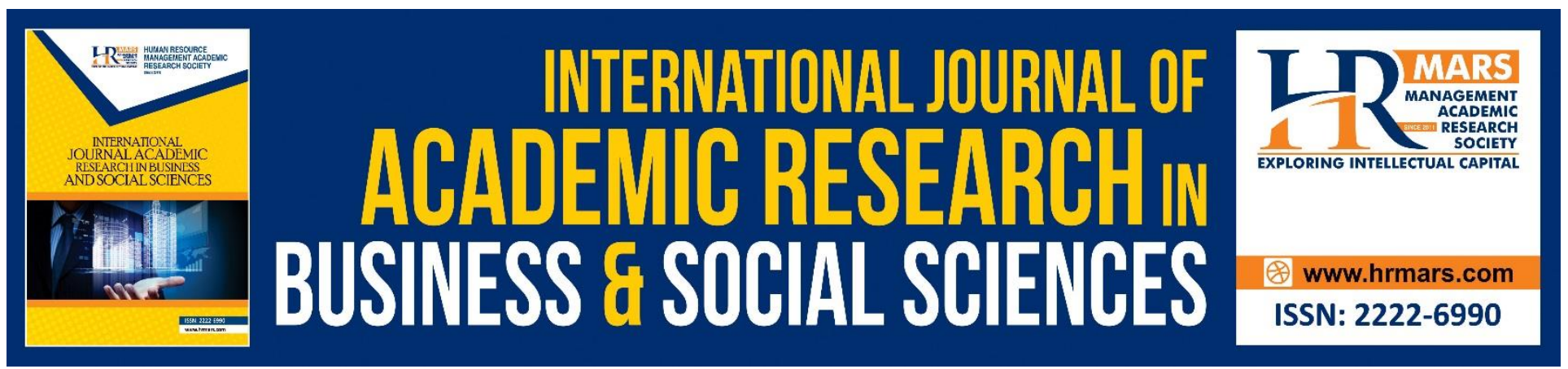

\title{
The Effects of Financing Sports Activities on International Sports Performance and on the Population's Health
}

\author{
Razvan Dorel Pauna, Alexandra Pintea \\ Babes-Bolyai University of Cluj Napoca, Faculty of Political, Administrative and Communication \\ Sciences, Department of Public Administration and Management \\ Email: razvanpaunaubb@gmail.com \\ Paul Sorin Lazar \\ Babes-Bolyai University of Cluj Napoca, Faculty of Business, Department of Hospitality Services
}

\section{Doru Maier}

Technical University of Cluj Napoca, Faculty of Machine Construction, Department of Management and Economic Engineering

\begin{abstract}
Sports activities have an increasingly important role in contemporary societies. Academic research is increasingly investigating topics related to sports financing, economic effects, sports business, effects on human social capital, etc. Our study looks at the effects of basic and extended funding for sport on a sample of 32 European countries, most of which are members of the European Union. The data are provided by international institutions such as the World Bank, World Health Organization, Global Health Observatory, Global Association of International Sports Federations and national sport institutions from the sampled countries. The results of the OLS cross-country regressions clearly demonstrate the positive role of sports financing on sports performance in international competitions, life expectancy and population health. Based on the results from the regressions, the real sports performances of the countries are analyzed compared to the hypothetical performances conditioned by a certain level of financing and of the gross domestic product. As a result of the main findings, recommendations are formulated regarding future studies and policies of regulatory institutions.
\end{abstract}

Keywords: Sports Financing, Life Expectancy, General Health of the Population, European Countries.

Introduction and Literature Review

Sport, both amateur and professional, has become an important economic and social phenomenon in many contemporary societies. Its impact is easily identifiable through its appearances in the daily 
INTERNATIONAL JOURNAL OF ACADEMIC RESEARCH IN BUSINESS AND SOCIAL SCIENCES Vol. 10, No. 10, 2020, E-ISSN: 2222-6990 @ 2020 HRMARS

life of the population, but also in the press. However, sport is an often underestimated sector. In recent decades, the economy of sport has grown considerably. The annual growth rate is more than twice as fast as world GDP. Sport is regularly presented by OECD sources as a new growth opportunity due to its resistance to cyclical shocks and the many externalities it generates. Today, sport is a powerful economic engine, creating wealth and jobs.

This topic then forces us to question the impact of the sports sector on the economy and more precisely on GDP. We will first detail some aspects related to the financing of sport, be it public or professional. Then we will address the subject of the sports-related market, especially the market for sports goods and sports services.

A difficult issue is the precise measurement of financial flows related to the sports sector, as there are no national sports accounts. In general, in European countries, this flow is measured in relation to national sports spending. The financing of the sport is due to the contribution of four major entities:

$>$ The state, whose financial support is important and runs mostly through sports ministries.

$>$ Sports movement, which brings together graduates, volunteers and sports associations affiliated to sports federations, grouped within the National Olympic Committee.

Local authorities, especially municipalities and inter-communities.

$>$ Private companies, acting as employers, advertisers or through investments.

\section{Public funding}

Public investments are regulated by various entities, from the Ministry of Sports to municipalities. The Ministry responsible for sport defines the main objectives of the national sports policy both at the level of high level sports and in the field of education and promotion of sports activities for the citizen. The amounts paid by the ministry come from the budget granted to it and from the revenues of the national centers for the development of sport, which is public under the coordination of the minister of sports. For example, in France, in 2017, the Sport program was funded with 521 million euros, of which 260 million euros came from the National Center for Sport Development - CNDS (King, 2013). Also, other ministries can also finance sports activities. For example, the Ministry of National Education provides training and remuneration to teachers of physical education and university sports facilities. Likewise, the Home Office can also promote physical activity and dedicate part of their budgets. Since 2006, CNDS, formerly the National Fund for the Development of Sport (FNDS), has been the only one able to provide equipment subsidies to sports associations or local authorities.

\section{Local authorities}

Municipalities, departments and regions are the main actors in public funding of sport. In the field of investments related to sports equipment, the municipal sector is the main public financier. Often, most of the municipal funding is spent on the management of sports facilities. The purpose of municipalities is to provide access to a large number of people to practice physical activity and sports. Thus, in 2012, in France, the municipal sector spent 10.8 billion euros out of a total public expenditure of 16.8 billion euros (King, 2013). 
INTERNATIONAL JOURNAL OF ACADEMIC RESEARCH IN BUSINESS AND SOCIAL SCIENCES Vol. 10, No. 10, 2020, E-ISSN: 2222-6990 @ 2020 HRMARS

\section{Private financing}

In the case of private financing, the two major investors are households and businesses. Companies intervene mainly as sponsors, while households can intervene through the volunteer, as an athlete or spectator. The household's sports consumption is very varied, from sporting goods such as clothing to tickets to sports events, gyms or swimming pools. In the case of households, these are mainly expenditures related to recreational sports, then high-level sports, ie sports entertainment and, finally, competitive amateur sports. However, sports-related shows are only a small part of their expenses. Volunteering is also an integral part of sport. It contributes to its proper functioning, but also to its development. Globally, at European level, 34\% of volunteers work in the sports sector. Business investments in sports are mainly based on sponsorships and partnerships with brands or athletes. For companies, sport is a means of communication and advertising that allows them to achieve their goals. In this way, both parties involved win. Thus, the company gains visibility, and the athlete, for example, gains funding. Today's sports sponsors come largely from luxury brands, the automotive or pharmaceutical industry, banking, electronics, transportation, the media itself, that is, from almost every economic sector. Sports sponsorship in European Union was valued at \$ 247 billion in 2018, a figure that continues to grow today.

Sports activity creates training markets for other sectors of the economy. Playing sports leads to the consumption of goods and services, but also has a considerable impact on industry, employment and the tertiary sector. Therefore, it is reasonable to say that the sports sector influences economic development at local, regional and national level. Sports markets are experiencing the highest growth in the consumer goods market in the last five years, with a growth rate of $2 \%$ per year. The sports market accounts for around $€ 225$ billion in the European Union alone, which is equivalent to around $1.8 \%$ of GDP. According to analysts, the sports market is now estimated at over 800 billion euros worldwide.

\section{Sports goods market}

The costs of sports practice are necessary, regardless of the specific equipment required or the cost of a subscription to the gym. Europeans spend an average of 253 euros a year on sporting goods. In terms of the market, the segment of articles and sportswear ranks 4th on the consumer goods market (Trenberth, 2012). This market offers several different and varied products, which allows companies to carry out different types of sales policies, with the help of the sponsor, they can set a certain range, can make promotional sales or even retain customers through an associated brand.

The characteristics of demand force the offer to adapt to a very diverse but still dynamic sporting goods market. It should be noted that this market is now strongly open to foreign countries, as can be seen in most sportswear and therefore strongly marked by the external market. The field of sport is also undergoing a transformation, this is due to the emergence of new specialized digital platforms. This represents about $30 \%$ of the market (Trenberth, 2012). The sporting goods market can also be innovative, so the use of new materials by companies in the production of their articles can change their physical properties and performance. For example, the arrival of mandatory boxing gloves in boxing matches in 1866 changed the position and tactics of boxers. In 2019, the sports goods market generated sales, without taxes, of approximately 71 billion. 
INTERNATIONAL JOURNAL OF ACADEMIC RESEARCH IN BUSINESS AND SOCIAL SCIENCES Vol. 10, No. 10, 2020, E-ISSN: 2222-6990 @ 2020 HRMARS

\section{Sports services market}

Today, sport is a strong part of our culture. Take, for example, sports shows such as football, tennis or volleyball. Participation in sports shows is explained by many factors, each of which has a strong influence on demand. Often, the following criteria are found: the quality of the show, the fame of the athletes or teams, their ranking, etc. Thus, two same sporting events do not have the same value in the eyes of everyone. The demand for sports performances by a part of the population has led to the creation of specialized sports programs. Television stations have begun offering such programs. They acquire the right to broadcast certain programs in exchange for payment of the costs of broadcasting or retransmission. That is why the television rights market has seen significant growth in recent years. The market for TV broadcasting rights in the European Union for sports competitions was valued at $\$ 207$ billion in 2018. The economic reasons that push the media to broadcast information or sports programs are primarily based on their own interests. The world of sports media is a thriving market. The demand for sports programs is growing. This is easily confirmed by the increase in the annual duration of sports programs. The most popular sports programs contribute to the advertising revenue of the channels and attract many important advertisers in periods of high audience. For example, broadcasting international sports shows, such as the World Cup, gets exceptional media ratings. In addition, hosting international sporting events such as the Olympic Games is a major development opportunity for an economy. Take the example of men's professional clubs. Despite the declining GDP dynamics, the sharp increase in the turnover of these professional clubs should be noted. We can see in the European Union an increase of about $44 \%$ in football revenues and about $11 \%$ for volleyball in the period 2010-2014.

We have already highlighted the complex relationship between sport and the economy. In recent years, sports, both amateur and professional, have entered the market era. With this came all its consequences involving its financing, media coverage or organization. The question today is what is the real economic value of sport? Knowing that we must not forget to include all the externalities that sport generates. Whether they are positive (economic development, tourist attraction, regional planning, etc.) or negative (doping, strong monetization of sport, corruption, etc.). Taking into account the multiplier effects it generates, the share of sport in the economy has been estimated at 2.98\% of GDP by the European Commission. In order to finally evaluate sport at its true value, it must be well organized and create a real sports economy.

The academic literature studies in many cases the sports phenomenon in connection with other fields of scientific interest: economics, business, finance, social sciences, public health, etc. The topics approached are very diverse: national and international organizational structures, public and private financing, business models in sports, the efficiency of compensation systems, the role of mass media, the contribution to the formation of social-human capital, etc.

\section{Sport and economics}

Petry, Steinbach and Tokarski (2004) provide an overview of the similarities and differences between sports systems in European countries. The main responsibilities of numerous national and local government institutions are analyzed, as well as the role and involvement of private and civil bodies. The variability of the involvement of state structures in the member countries of the European Union is very high, from clear specifications in the fundamental constitutional law to a total independence 
INTERNATIONAL JOURNAL OF ACADEMIC RESEARCH IN BUSINESS AND SOCIAL SCIENCES Vol. 10, No. 10, 2020, E-ISSN: 2222-6990 @ 2020 HRMARS

of amateur and professional sport. The various aspects of financial support in the sample countries are analytically investigated. The most important common point of European sport is also identified, which is the hierarchical organizational structure of the pyramid. Some studies (Begovic, 2020) provide a detailed description of a system of sports policy and organization at the national level. A critical interpretation of the traditional social and economic aspects of sport is provided by Bourg and Gouguet (2010). They perform relevant analysis of performance sports and define alternative bases for contemporary functional models. The authors demonstrate that professional sport is an extremely complex phenomenon that includes many specific factors, depending on its area of coverage, funding and territorial organization. Unusual aspects in specific situations are highlighted by King (2013), who evaluates the actions of local authorities in the United Kingdom in the field of sport in the context of the global financial crisis of 2008. Using a sample of amateur athletes, the relative decline of sport for all is demonstrated. The potential strategies for increasing sports activity among citizens are also being investigated comparatively. In the "insurance board" model, sports services retain the basic capacity to model and provide services in an increasingly fragmented mixed local economy for the provision of sports services. In contrast, models that favor the expansion of private or voluntary sector and community management represent significant challenges for local authorities councils that want to keep amateur sport as an important component of public services. Sandy (2017) conducts a theoretical and empirical study in which he applies in theory the theories and techniques of analysis from economics and management. The vision of the application, which includes numerous case studies is a global one, with regional specificities from Europe, America and Asia. Sport from its global business perspective is examined by Gratton et al. (2012). Large-scale sporting events such as the Olympic Games or the Football World Cup reach all territories on Earth in visibility. They are managed by transnational regulators, such as the IOC, FIFA or UEFA, which operate on organizational systems similar to multinational corporations. Large sports equipment companies such as Adidas, Lotto, Puma or Nike design, produce, distribute and market their products on all continents. An increasingly important part of the national markets for sports clothing, equipment and accessories is internationalizing. The authors study the economics of sport in contemporary societies using the international market as an essential landmark of analysis. Numerous empirical data are used to define and analyze the sports market and most of its components. The case studies cover different geographical areas in Europe, America and Asia. Makes an introduction to the theory and practice of sports management. In today's society, sport has become a huge and elaborate global business and, at the same time, a high-volume participatory activity, led mostly by volunteers and community organizations (Trenberth, 2012). The essential functional areas of sports management are explored, from organization and strategy to financing and marketing. The techniques by which successful managerial actions can be applied in a sports context are explained. Some major issues in the management of contemporary sport are reviewed, from corporate social responsibility to the use of information and communication technologies. Litivishko (2019) argues that in the contemporary economic paradigm, professional national sports can generate international performance only if they are adequately funded by governments and private organizations. National sports industries strive to identify effective ways of collaboration between private and public structures to develop. The analysis shows that sports success comes from the commercial success that allows the reinvestment in sports of a part of the income generated by economic activities (Howard, 2019). In this context of successful policies and practices, traditional national mechanisms for financing sport do not seem satisfactorily effective. In most cases, 
INTERNATIONAL JOURNAL OF ACADEMIC RESEARCH IN BUSINESS AND SOCIAL SCIENCES Vol. 10, No. 10, 2020, E-ISSN: 2222-6990 @ 2020 HRMARS

responsible public agency institutions face budgetary constraints, and sports clubs are required to make additional use of sponsors and donors to ensure the financial sustainability of sports activities. Garner, Humphrey and Simkins (2016) provide an overview of human capital in national sports markets, but also of the link between sport and corporate finance. The evaluated empirical studies show a strong correlation between sports performance and financial compensation. The material compensation practices used by the sports business are also investigated in comparison.

\section{Media, events and social capital}

The effect of new media technologies on changing production and consumption in professionally practiced sports is investigated by Dart (2014). He concludes that current trends continue the existing neoliberal capitalist directions in performance sports. Using concepts from the concept of political economy, the problems of ownership, structure and production of sport are explored. The analysis focuses on the opportunities that sports fans now have at their disposal and how the sports organization and media corporations have moved from an initial position of uncertainty, close to rejection, to one that surprised them by agreeing with new media technologies as appropriate tools. efficient marketing. A model of sports integration is proposed and analyzed by Chalip et al. (2017). Three component elements are evaluated: (1) the hierarchical nature of the context (culture; opinions and attitudes; systems and structures), (2) three types of organizations with a stake in the leverage process (event, sport and non-sports entities) and (3) the necessary resources (human, physical and knowledge). The overall conclusion shows that sporting events can be used to increase participation in sports activities if the main collaborations between sports associations, large event managers and non-sporting participants are put together to integrate each event into the marketing mix of sports organizations. . The role of sport in creating and maintaining the social and human capital of a society is investigated by Spaaij and Westerbeek (2010). The effect that sports business organizations have on the formation of social capital is also studied. The links between the activities carried out by sports business organizations and the different types of social capital that these activities can generate are followed.

\section{Sport and health}

A relatively classic topic that studies the relationship between sport and health has become increasingly complex through the side implications it generates. The percentages of population participation in sports activities are very diverse from one country to another (Khan et al. 2012). Although there is little data to assess trends in sports participation, there is little evidence of change in the last decade among adults. Studies on large samples show that such participation in sports is associated with a $20-40 \%$ reduction in all-cause mortality compared to people who do not play sports. Empirical medical studies show that playing sports is associated with specific health benefits. Exercise should be considered a vital sign and should be recorded in patients' medical records. Recently, research in the field of sports, health, and physical education has increasingly accepted the salutogenic model of health that conceptualizes the relationship between activity or physical education and health (McCuaig and Quennerstedt, 2018). The authors suggest that salutogenic researchers have missed opportunities to explore the sociological aspects of the problem. The generative possibilities that social theory highlights for those who want to inform and design salutogen-oriented sports programs for children and young people are demonstrated. Policymakers are increasingly considering the fact that sport, as a form of physical activity, can be a tool to promote 
INTERNATIONAL JOURNAL OF ACADEMIC RESEARCH IN BUSINESS AND SOCIAL SCIENCES Vol. 10, No. 10, 2020, E-ISSN: 2222-6990 @ 2020 HRMARS

general health and also subjective well-being (Downward, Hallmann and Rasciute, 2018). Subjective well-being, on the other hand, is broader, encompassing broader psychological and life satisfaction, as well as mood and emotional distress. Past and present policies also identify a link between sport, social capital and subjective well-being. The results of the regressions used in the application also show that there is no relationship between social capital and sport, but a clear relationship between subjective well-being and social capital. From a health policy perspective, the emphasis should be on encouraging increased participation in sport, despite the difficulties it poses, as there is a potential multiplier effect on subjective well-being and overall health through mediation.

\section{Objectives, Hypotheses, Variables and Methodology}

Our study has the following two main objectives

- Using as a theoretical basis the cited academic literature and using cross-section linear regressions, we highlight the correlations between the basic and extended financing of sports activities and elite sports performance at national level.

- Demonstrating the role of financing of sports activities as a factor influencing life expectancy and the general state of health of the citizens.

As a result of the specialized literature in the field of sports and our reasoning, we formulate three testable hypotheses:

H1. The basic and extended financing of the sport are determinants for the elite sports performance at national level.

H2. Life expectancy at the national level is influenced by the basic and extended financing of sports.

H3. The general state of health of the citizens of a country is influenced by the budgetary financing for sports.

\section{Variables}

ELITE_POINTS

The national score obtained in the ranking WRCEC. The World Ranking of Countries in Elite Sport (WRCEC) is a research-based annual ranking measuring accurately the performance of all the countries having National Olympic Committees based on their international results in all the sports recognized by GAISF (Global Association of International Sports Federations) and in other sports, not yet part of GAISF, but having high popularity and universality.

\section{Population}

Total population is based on the de facto definition of population, which counts all residents regardless of legal status or citizenship. The values shown are midyear estimates. Source: World Bank (2018). 
INTERNATIONAL JOURNAL OF ACADEMIC RESEARCH IN BUSINESS AND SOCIAL SCIENCES Vol. 10, No. 10, 2020, E-ISSN: 2222-6990 @ 2020 HRMARS

\section{ELITE SPORT}

It is a variable obtained as a ratio between ELITE_POINTS and the square root of the number of inhabitants in the respective country. Some preliminary calculations have indicated that ELITE_POINTS is more correlated with the square root of the population than with other mathematical transformations of the POPULATION variable (logarithms, roots, etc.).

\section{LIFE_EXPECTANCY}

Life Expectancy at birth indicates the number of years a newborn infant would live if prevailing patterns of mortality at the time of its birth were to stay the same throughout its life (for the distribution of the values in the sample see Appendix 1). Source: World Bank (2018).

\section{Daly}

Disability-Adjusted Life Years (DALYs) per 100,000 individuals from all causes. DALYs measure the total burden of disease - both from years of life lost due to premature death and years lived with a disability. One DALY equals one lost year of healthy life. Mortality does not give a complete picture of the burden of disease borne by individuals in different communities. The summary measure used to give an indication of the burden of disease is the DALY. One DALY represents the loss of the equivalent of one year of full health. Using DALYs, the burden of diseases that cause early death but little disability (eg. drowning or measles) can be compared to that of diseases that do not cause death but do cause disability (e.g. cataract causing blindness). Source: World Health Organization, Global Health Observatory and Ourworldindata.org (2018).

GDP_CAP

GDP per capita $\left(10^{3} \$\right)$ is gross domestic product divided by midyear population. Source: World Bank (2018).

\section{BASIC_FUND}

Basic sports financing (\%o GDP). This represents the total funding for all activities which are inputs to sport (i.e. all goods and services which are necessary for doing sport) plus the direct sports activities (indemnities for athletes and coaches, financing for participation in competitions, etc.). Source: Publications Office of the EU, Study on the contribution of sport to economic growth and employment in the EU (2018) and national sport institutions from the sampled countries.

\section{EXTEND_FUND}

Extendend sport financing (\% GDP). This represents the total funding for all activities which require sport as an input (i.e. all goods and services which are related to a sport activity but without being necessary for doing sport) plus the This represents the total funding for basic sports financing. Source: Publications Office of the EU, Study on the contribution of sport to economic growth and employment in the EU (2018) and national sport institutions from the sampled countries.

\section{Results and Discussion}

To test the hypotheses we chose a linear specification of the model and estimated the coefficients using OLS regressions. The data from our study refer to 32 European countries. Their choice was not 
INTERNATIONAL JOURNAL OF ACADEMIC RESEARCH IN BUSINESS AND SOCIAL SCIENCES Vol. 10, No. 10, 2020, E-ISSN: 2222-6990 @ 2020 HRMARS

made by sampling, all European countries were included for which data are available for all variables included in the application.

The list of the 32 countries in the sample includes the states of the European Union (in 2018), plus Iceland, Switzerland, Norway and Turkey, respectively: Austria (AT), Belgium (BE), Bulgaria (BG), Croatia (HR), Cyprus (CY), Czech Republic (CZ), Denmark (DK), Estonia (EE), Finland (FI), France (FR), Germany (DE), Greece (GR), Hungary (HU), Iceland (IS), Ireland (IE), Italy (IT), Latvia (LV), Lithuania(LI), Luxemburg (LU), Malta (MT), Netherlands (NL), Norway (NO), Poland (PL), Portugal (PT), Romania (RO), Slovakia (SK), Slovenia (SI), Spain (ES), Sweden (SE), Switzerland (CH), Turkey (TR) and United Kingdom (UK).

Table 1: Descriptive statistics of variables

\begin{tabular}{|l|c|c|c|c|}
\hline Variable & Min. & Max. & Mean & St. dev. \\
\hline ELITE_POINTS & 94107 & 979438 & 330437 & 208922 \\
\hline POPULATION (thausands inhabitants) & 353 & 82906 & 19054 & 24961 \\
\hline ELITE_SPORT & 906 & 7593 & 3518 & 1400 \\
\hline LIFE_EXPECTANCY (years) & 74.8 & 83.8 & 80.3 & 2.73 \\
\hline DALY & 17003 & 27525 & 20623 & 3068 \\
\hline GDP_CAP (thousands \$) & 9.37 & 116.7 & 39.28 & 25.48 \\
\hline BASIC_FUND (\%o GDP) & 0.144 & 10.21 & 4.91 & 2.27 \\
\hline EXTEND_FUND (\%o GDP) & 0.172 & 19.41 & 7.64 & 4.29 \\
\hline
\end{tabular}

Source: authors' calculations using data from Insurance World Bank, World Health Organization, Global Health Observatory, Global Association of International Sports Federations and national sport institutions

Descriptive statistics (Table 1) intuitively foreshadow some results. Endogenous variables ELITE_SPORT, LIFE_EXPECTANCY and DALY do not have the same variability. This may indicate that the degree of their determination by explanatory variables may be very different. We also notice very large variations in the percentages of public financing of sports. This result has two sources. First of all, the richer countries do not have very high budgetary constraints and can afford to allocate significant sums for the direct or indirect support of sports activities. Secondly, we can talk about different national policies, from countries that mainly finance sports through financing and public policies to countries that leave these mechanisms to the private sector. 
INTERNATIONAL JOURNAL OF ACADEMIC RESEARCH IN BUSINESS AND SOCIAL SCIENCES

Vol. 10, No. 10, 2020, E-ISSN: 2222-6990 @ 2020 HRMARS

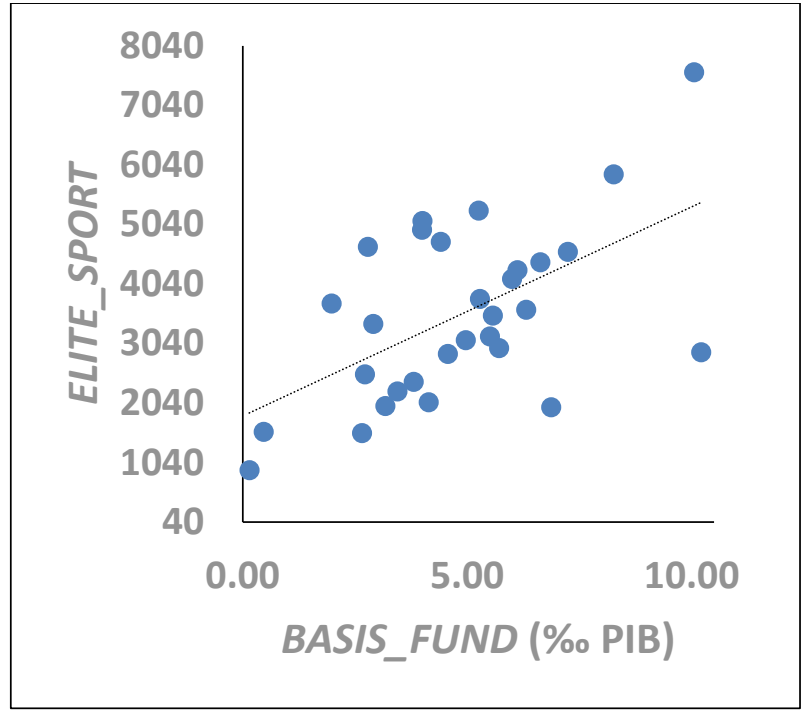

Fig. 1: Linear correlation between BASIC_FUND and ELITE_SPORT (authors' calculations)

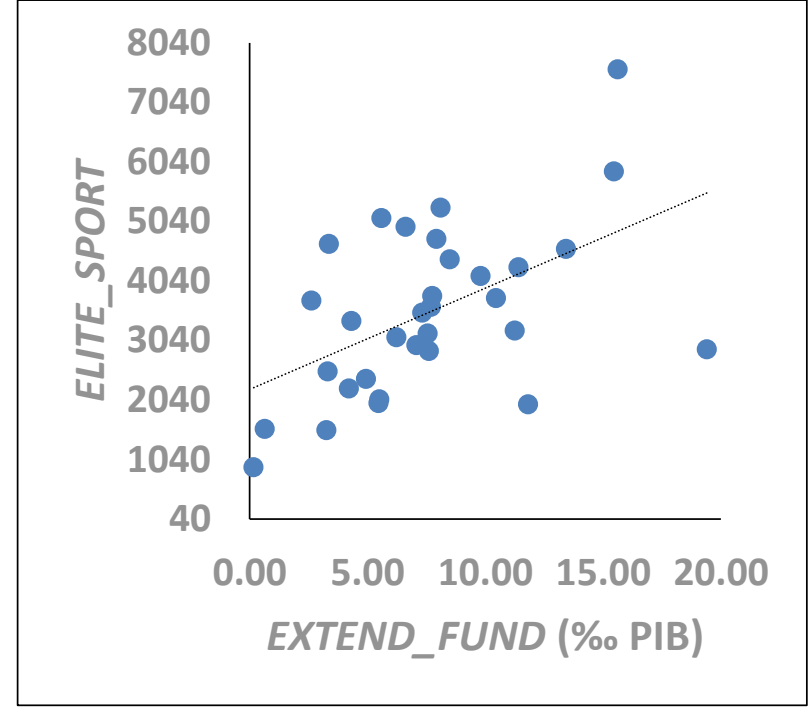

Fig. 2: Linear correlation between EXTEND_FUND and ELITE_SPORT (authors' calculations)

Figures 1 and 2 show that the correlation between the endogenous variable LELITE_SPORT and the explanatory quantitative variables BASIC_FUND and ELITE_FUND is not linear. The same result is supported by calculations (correlation coefficients), the linear specification being more adequate than the nonlinear specifications (logarithmic, polynomial, etc.).

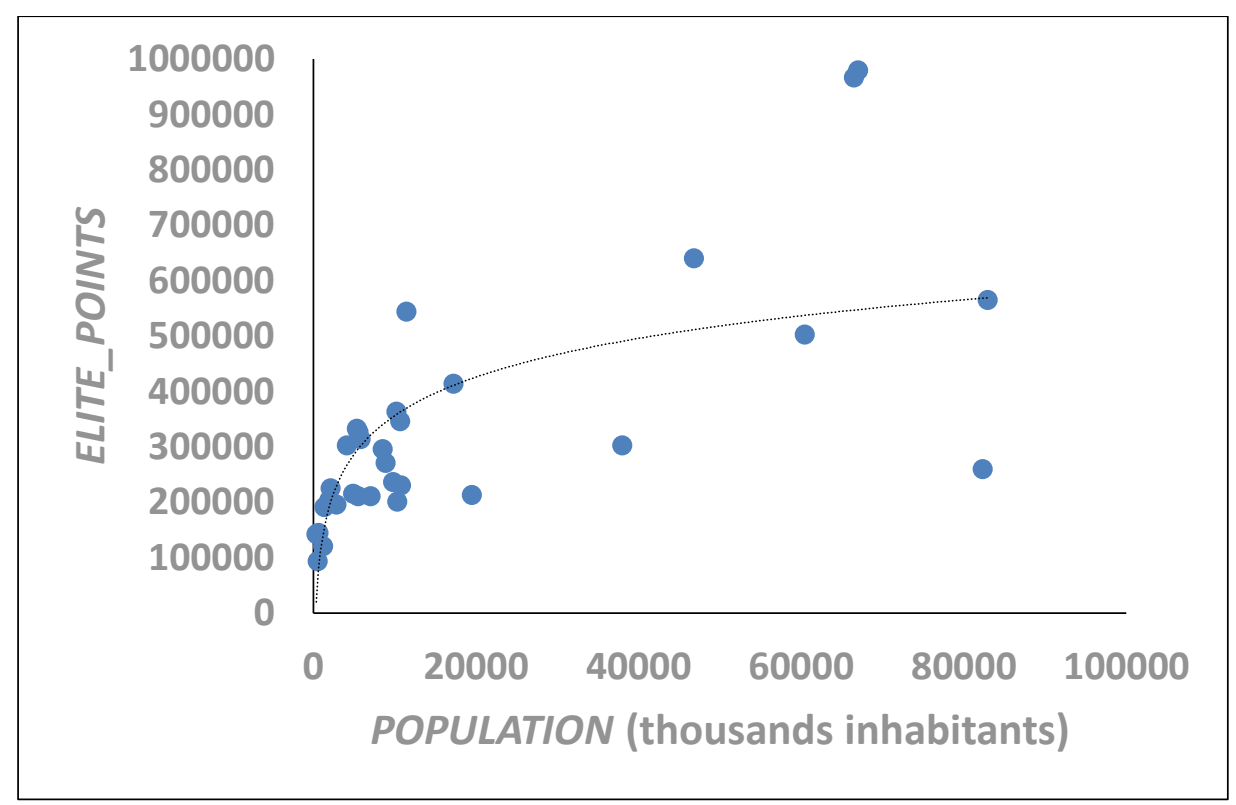

Fig. 3: Nonlinear correlation between PULATION and ELITE_POINTS (authors' calculations)

In contrast, the correlation between a country's total performance in elite competitions (ELITE_POINTS) and the country's population (POPULATION) is not linear (Figure 3). This result is explained by the fact that in most continental or world level competitions each country is allowed to participate with a limited number of athletes or teams. However, there are two important factors 
INTERNATIONAL JOURNAL OF ACADEMIC RESEARCH IN BUSINESS AND SOCIAL SCIENCES Vol. 10, No. 10, 2020, E-ISSN: 2222-6990 @ 2020 HRMARS

why countries with a larger population get more important results in professional sports. First of all, the basis of selection, ie the number of people who practice sports is higher. Second, larger countries manage to participate with players and teams from numerous sports. Consequently, in order to measure the intensity, not the absolute value of the sports results of a country in elite competitions, we will use in the regressions the variable ELITE_SPORT. This is obtained as the ratio between ELITE_POINTS and the square root of the population in that country. The calculation of the correlation coefficients and the graphical study of the distributions (Figure 3) indicated that ELITE_POINTS is more correlated with the square root of the population than with other mathematical transformations of the POPULATION variable (logarithms, roots, etc.).

Table 2: The coefficients of the OLS regressions on ELITE_SPORT (coefficients and $t$-stat)

\begin{tabular}{|l|r|r|r|}
\hline & \multicolumn{3}{|c|}{ Dependent variable: ELITE_SPORT } \\
\hline & OLS 1 & OLS 2 & \multicolumn{1}{c|}{ OLS 3 } \\
\hline BASIC_FUND & $* * 286.6(2.10)$ & & $408.3(1.19)$ \\
\hline EXTEND_FUND & & $* 125.2(1.72)$ & $-69.15(-0.39)$ \\
\hline GDP_CAP & $7.031(0.58)$ & & $7.446(0.60)$ \\
\hline Constant & $* * * 1835(3.60)$ & $* * * 2146(4.71)$ & $* * * 1750(3.11)$ \\
\hline & $\mathrm{R}^{2}=0.320$ & $\mathrm{R}^{2}=0.289$ & $\mathrm{R}^{2}=0.323$ \\
\hline
\end{tabular}

$* * *, * *, *$ : significant at $1 \%, 5 \%$ and $10 \%$ level

Source: own calculations using STATA 14 software.

We note first of all that the public financing granted to sport, in any of its two forms (BASIC_FUND and EXTEND_FUND) is statistically significant (OLS 1 and OLS2, see Table 2) on the national performance obtained in international competitions (ELITE_SPORT). In contrast, in the OLS3 regression, the two factors appear to be insignificant, but this is due to the strong correlation between them (Pearson coefficient $=0.959$, Table 6 ). It is interesting that the financing is significant even in the presence of GDP/capita as a control factor. Consequently, even for low-income countries, so small amounts allocated to sports, the high percentage of funding manages to highlight their own athletes. Basically, the attention given to sports by the authorities gives athletes a respectable status in society, managing to motivate them.

Table 3: The coefficients of the OLS regressions on LIFE_EXPECTANCY (coefficients and $t$-stat)

\begin{tabular}{|l|r|r|r|}
\hline & \multicolumn{3}{|c|}{ Dependent variable: LIFE_EXPECTANCY } \\
\hline BASIC_FUND & OLS 4 & OLS 5 & \multicolumn{1}{c|}{ OLS 6 } \\
\hline EXTEND_FUND & & & $0.943(1.68)$ \\
\hline GDP_CAP & $* * 0.045(2.23)$ & $* * 0.054(2.65)$ & $* 0.297(-1.02)$ \\
\hline Constant & $* * * 76.43(90.7)$ & $* * * 76.42(101.4)$ & $* * * 76.1(83.1)$ \\
\hline & $\mathrm{R}^{2}=0.0 .512$ & $\mathrm{R}^{2}=0.482$ & $\mathrm{R}^{2}=0.530$ \\
\hline
\end{tabular}

$* * *, * *, *$ : significant at $1 \%, 5 \%$ and $10 \%$ level

Source: own calculations using STATA 14 software. 
INTERNATIONAL JOURNAL OF ACADEMIC RESEARCH IN BUSINESS AND SOCIAL SCIENCES Vol. 10, No. 10, 2020, E-ISSN: 2222-6990 @ 2020 HRMARS

Table 4: The coefficients of the OLS regressions on DALY (coefficients and $t$-stat)

\begin{tabular}{|l|r|r|r|}
\hline & \multicolumn{3}{|c|}{ Dependent variable: DALY } \\
\hline BASIC_FUND & OLS 7 & \multicolumn{1}{c|}{ OLS 8 } & \multicolumn{1}{c|}{ OLS 9 } \\
\hline EXTEND_FUND & & & $*_{-}-1192(-1.77)$ \\
\hline GDP_CAP & $-37.73(-1.55)$ & $*-49.07(-1.99)$ & $-39.95(-1.64)$ \\
\hline Constant & $* * * 24751(24.4)$ & $* * * 24051(26.2)$ & $25207(22.89)$ \\
\hline & $\mathrm{R}^{2}=0.439$ & $\mathrm{R}^{2}=0.400$ & $\mathrm{R}^{2}=0.461$ \\
\hline
\end{tabular}

$* * *, * *, *$ : significant at $1 \%, 5 \%$ and $10 \%$ level

Source: own calculations using STATA 14 software.

Sport funding also has similar positive effects (OLS 5-9, Tables 3 and 4) on life expectancy and population health $(D A L Y)$. We find instead that the variable GDP_CAP becomes statistically significant especially on LIFE_EXPECTANCY. The result is explicable by the factors that this variable hides. High incomes of the population are associated in most cases with good quality health systems. However, this effect of wealth is not as strongly reflected on the health of the population, this being largely determined by other factors such as eating habits, activities involving physical exertion, etc. As a result of the results generated by the regressions, we fully accept hypotheses $H 1$ and $H 2$. We can only partially validate the $\mathrm{H} 3$ hypothesis because the significant role of EXTEND_FUND on population health has not been demonstrated.

Table 5 : The matrix of the correlation (Pearson) coefficients

\begin{tabular}{|l|c|c|c|c|c|c|}
\hline & (1) & (2) & (3) & (4) & (5) & (6) \\
\hline ELITE_SPORT (1) & 1.000 & & & & & \\
\hline LIFE_EXPECTANCY (2) & 0.202 & 1.000 & & & & \\
\hline DALY (3) & -0.149 & -0.973 & 1.000 & & & \\
\hline BASIC_FUND (4) & 0.559 & 0.655 & -0.626 & 1.000 & & \\
\hline EXTEND_FUND (5) & 0.521 & 0.597 & -0.564 & 0.959 & 1.000 & \\
\hline GDP_CAP(6) & 0.466 & 0.674 & -0.603 & 0.725 & 0.712 & 1.000 \\
\hline
\end{tabular}

Using the OLS1 regression coefficients we generated the estimated values of the ELITE_SPORT variable. These can be interpreted as "normal" values of sports performance under the conditions of certain values of sports financing and GDP per capita. We calculated the relative difference (as a percentage) between the effective sports performance of a country and the "normal" one. The results (Figure 4) show which countries are outperforming and which are in the opposite situation. We note first of all that there is no clustering of countries on geographical or economic criteria. Among the top performing countries in sports we notice both relatively poor countries in Europe (Romania and Turkey), but also well-developed countries such as Germany, Austria and Italy. The way these countries have reached the top can be very different from one case to another. In some situations, economic development has led to a large number of professional athletes in all sports, and performance has come as a consequence. In other cases, despite low funding, performance came as a result of the highly motivating social position of top athletes in the country. On the other hand, among the under-performing countries there are not necessarily nations that do not love sports. The 
INTERNATIONAL JOURNAL OF ACADEMIC RESEARCH IN BUSINESS AND SOCIAL SCIENCES Vol. 10, No. 10, 2020, E-ISSN: 2222-6990 @ 2020 HRMARS

situation seems to be rather generated by other factors. In some societies, amateur sports are rather encouraged. In other cases, there is a strong preponderance of team sports over individual ones (eg Croatia), but they bring fewer points and medals to international competitions.

For a more pertinent analysis of the positioning of the countries in relation to professional sports, a separate study should be carried out, which should take into account the situation by sports disciplines, or at least to dissociate team sports from individual sports. Also, we should have data that is more difficult to procure at the moment, regarding the destination of the sums of money from the financing of the sport, that is to what extent they go to the amateur sport, respectively to the professional one.

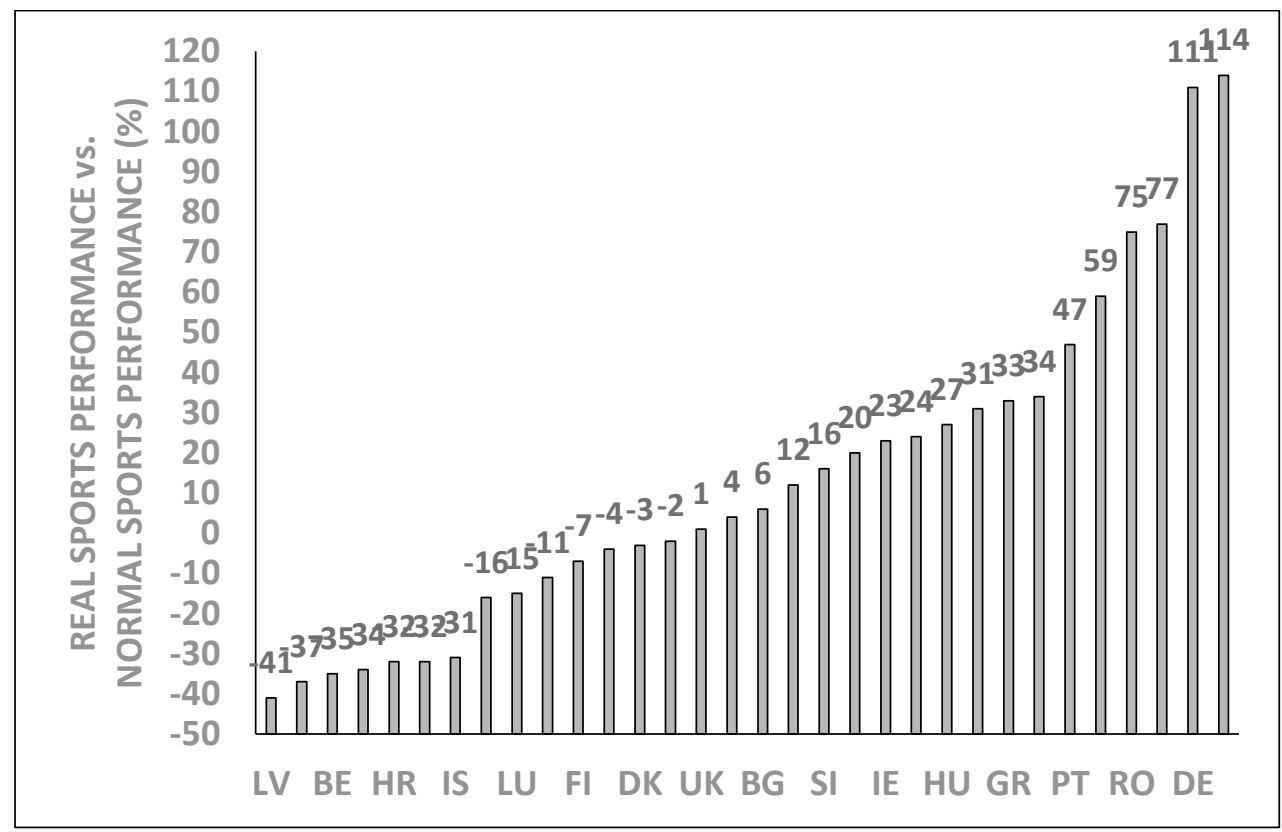

Fig. 4: The relative difference between the real sports performance and the "normal" one related to a certain financing of the sport and the GDP

\section{Conclusions}

Our study is not intended to exhaustively explain the factors that determine international sports performance, life expectancy and general health of the population. However, we managed to highlight the positive influence of the financing of the sport, both the basic one and the extended one. Of course, there are limitations to the study, but they open up future directions for research. The variables used as a proxy for sports performance should be more detailed. For example, discrimination between team sports and individual sports could bring more clarity on the efficiency of the use of funds dedicated to sport. Team sports bring fewer points and medals in competitions at the continental and world level, instead they involve a greater number of athletes at all value levels, which can generate positive effects on the health of the population. Public institutions should find an optimal level of funding for sports activities, as there is a trade-off effect between increasing sportsrelated spending and reducing those for health care and prevention. In addition, all these mechanisms involve national and regional specificities that should be studied. However, the practice of sports brings proven benefits for the population, and the financing of these activities can only 
INTERNATIONAL JOURNAL OF ACADEMIC RESEARCH IN BUSINESS AND SOCIAL SCIENCES Vol. 10, No. 10, 2020, E-ISSN: 2222-6990 @ 2020 HRMARS

increase these advantages. This article contributes to the current level of academic research primarily through the empirical results obtained on European countries. We highlighted the causal relationships between the financing of the medical system, the development of private health insurance, life expectancy, the quality of the medical system and the decentralization of the organization of health services. In addition, we have highlighted the linear and logarithmic functional forms between certain national characteristics. The functions that explain the correlations between the studied macroeconomic aggregates can later be used for some more detailed structural analyzes or even for short-term forecasts. It can be researched separately, for each nation if the performances obtained by athletes in international competitions are above or below expectations, conditioned by the level of financing sports activities.

\section{References}

Begovic, M. (2020). The development of sport policy in Montenegro. International Journal of Sport Policy and Politics, onlinefirst, 1-10.

Bourg, J. F., \& Gouguet, J. J. (2010). The political economy of professional sport. Edward Elgar Publishing.

Chalip, L., Green, B. C., Taks, M., \& Misener, L. (2017). Creating sport participation from sport events: Making it happen. International Journal of Sport Policy and Politics, 9(2), 257-276.

Dart, J. (2014). New media, professional sport and political economy. Journal of Sport and Social Issues, 38(6), 528-547.

Downward, P., Hallmann, K., \& Rasciute, S. (2018). Exploring the interrelationship between sport, health and social outcomes in the UK: implications for health policy. The European Journal of Public Health, 28(1), 99-104.

Garner, J., Humphrey, P. R., \& Simkins, B. (2016). The business of sport and the sport of business: A review of the compensation literature in finance and sports. International Review of Financial Analysis, 47, 197-204.

Gratton, C., Liu, D., Ramchandani, G., \& Wilson, D. (2012). The global economics of sport. Routledge.

Howard, D. R. (2019). Financing sport. International Journal of Sport Communication, 12, 306-309.

Khan, K. M., Thompson, A. M., Blair, S. N., Sallis, J. F., Powell, K. E., Bull, F. C., \& Bauman, A. E. (2012). Sport and exercise as contributors to the health of nations. The Lancet, 380(9836), 59-64.

King, N. (2013). "Sport for All" in a financial crisis: survival and adaptation in competing organisational models of local authority sport services. World leisure journal, 55(3), 215-228.

Litvishko, O. V., Vysotskaya, T. P., Bodrov, I. M., Nosov, S. M., \& Buyanova, T. V. (2019). Ways to improve efficiency of professional sports financing mechanisms. Theory and Practice of Physical Culture, (9), 34-34.

McCuaig, L., \& Quennerstedt, M. (2018). Health by stealth-exploring the sociocultural dimensions of salutogenesis for sport, health and physical education research. Sport, education and society, 23(2), 111-122.

Ourworldindata. (2018). Burden of Disease. Ourworldindata.org

Petry, K., Steinbach, D., \& Tokarski, W. (2004). Sport systems in the countries of the European Union: Similarities and differences. European Journal for Sport and Society, 1(1), 15-21.

PO of the EU. (2018). Study on the contribution of sport to economic growth and employment in the $E U$. Publications Office of the EU. 
INTERNATIONAL JOURNAL OF ACADEMIC RESEARCH IN BUSINESS AND SOCIAL SCIENCES Vol. 10, No. 10, 2020, E-ISSN: 2222-6990 @ 2020 HRMARS

Sandy, R. (2017). The economics of sport: An international perspective. Macmillan International Higher Education.

Spaaij, R., \& Westerbeek, H. (2010). Sport business and social capital: a contradiction in terms?. Sport in Society, 13(9), 1356-1373.

Trenberth, L. (2012). The sport business industry. In L. Trenberth \& D. Hassan (Eds.), Foundations of sport management. Managing sport business. An introduction (pp. 3-16). Milton Park, Abingdon, Oxon, and New York, NY: Routledge.

WHO (2018). Global Health Observatory, World Health Organization.

World Bank. (2018). Indicators: Economy \& Growth, Population. Washington, DC: World Bank. 